\title{
Open Strategy: Dimensions, Dilemmas, Dynamics
}

Julia Hautz, David Seidl, Richard Whittington

\begin{abstract}
Responding to increasing practitioner and academic interest in Open Strategy, this article builds on recent theoretical and empirical studies in order to advance research in the following ways. We begin by developing a definition of Open Strategy that emphasizes variation along the two dimensions of transparency and inclusion, as well as the dilemmas and dynamics inherent in its practices. We identify five dilemmas in particular: those of process, commitment, disclosure, empowerment and escalation. We continue by exploring key dynamics in Open Strategy, including both movements along the dimensions of transparency and inclusion, and movements between the two dimensions. Respecting the acute dilemmas of Open Strategy, we allow in each case for movement away from greater openness. The article concludes by proposing an agenda for future research on Open Strategy. KEYWORDS: Inclusion, Open Strategy, Participation, Strategy as Practice, Strategy Process, Transparency
\end{abstract}




\section{Introduction}

At its simplest, Open Strategy promises increased transparency and inclusion regarding strategic issues, involving both internal and external stakeholders (Whittington, et al., 2011). With openness, more strategic information is available, and more people are able to engage in the strategic conversation. However, building on a gathering body of research, we aim in this article to develop a more theoretically-nuanced understanding of Open Strategy, one capable of driving an ongoing research agenda. We will argue that Open Strategy should be seen as continuously varying along the two dimensions of transparency and inclusion, its dynamics driven by the sharp dilemmas posed by organizational and environmental contingencies.

To be sure, the practices associated with Open Strategy - for example, Chief Executive strategy presentations, 'jams', wiki conversations and the like - appear well-aligned with major trends in contemporary business. The spread of business education, the new social media technologies and the rise of interdependent ecosystems all favour more transparent and inclusive approaches to strategy (Whittington, et al., 2011). Open Strategy also promises many benefits, such as greater creativity due to larger, more diverse pools of contributors (Stieger, et al., 2012), increased commitment and joint sensemaking (Ketokivi and Castaner, 2004; Doz and Kosonen, 2008; Hutter, et al., 2017), and favorable impression management (Gegenhuber and Dobusch, 2017; Yakis-Douglas, et al., 2017). Yet, despite the power of these trends and benefits, the spirit of critical inquiry requires of us an approach to Open Strategy that remains alive to both ambivalence and reversion.

Accordingly, we develop from the articles in this Special Issue and from recent research published elsewhere a definition of Open Strategy that allows for the complexity and contingency required for further research. In this view, Open Strategy is a dynamic bundle of practices that affords internal and external actors greater strategic transparency and/or inclusion, the balance and extent of which respond to evolving contingencies derived from both within and without organizational boundaries. This definition aims to capture the varying degrees of transparency and inclusion, from modest to radical, found empirically, at the same time as recognizing how openness can switch from one dimension to another, or even be entirely reversed. This more nuanced approach also reflects how openness is not simply the product of general social, technological and economic forces, but sensitive to the particular and varying contingencies facing individual organizations. Under some conditions, Open 
Strategy can be dysfunctional. The evolution of Open Strategy is therefore likely to be uneven, with changes in direction according to local circumstances.

It is clear, then, that Open Strategy involves both general trends and specific applications. In this sense, the concept connects directly with the emerging 'macro' agenda in Strategy-asPractice research, an agenda focused on strategy practices with societal reach and significance (Suddaby, et al., 2013; Seidl and Whittington, 2014). Strategy-as-Practice research has always recognized the value of local accounts of strategizing activities in specific episodes (Hendry and Seidl, 2003), but has grappled less with strategy practices that have the capacity, as Open Strategy does, of transforming organizational relationships and responsibilities more widely in society. In taking advantage of economic, technological and social trends to give greater transparency and inclusion to actors inside and outside organizations, Open Strategy does have the potential for those kinds of 'macro' repercussions. Yet, as the articles we review here demonstrate, Open Strategy practices are also being continuously made and remade in particular organizations. Openness is simultaneously macro phenomenon and micro instantiation. As such, Open Strategy deserves large-scale, quantitative study across many organizations as much as close ethnographic observation in individual cases. Spanning different levels, and employing a range of quantitative and qualitative methodologies, research on Open Strategy can thus contribute to the melding of micro and macro approaches in Strategy-as-Practice research.

We believe therefore that Open Strategy is potentially a rich and productive concept, capable of capturing major trends in contemporary strategy practice at the same time as allowing for local variation. The phenomena it describes are highly diverse. As we shall show, many practices have been explored under different labels well-before the concept was even coined, and other established practices have been multiplied in both their extent and their effects by greater openness. However, as with the related umbrella concept of Open Innovation (Chesbrough, 2003; Trott and Hartmann, 2009), Open Strategy organizes a range of practices in order to assert fundamental similarities and mobilize joint-research. The concept directs attention to an increasingly widespread set of practices in contemporary organizations, ones that share in contrasting sharply with the deliberately opaque and elitist practices that prevailed in earlier modes of strategizing (Whittington, et al., 2011). The growing importance of the phenomenon, its potential benefits, and the complexities of enactment all demand further research. 
This article continues by exploring the benefits and complexities of Open Strategy as revealed by recent research. Drawing on this research, we first define more precisely the dimensions of transparency and inclusion, draw out some key dilemmas posed by Open Strategy, and then explicate its inherent dynamics. We conclude with an overarching agenda for future research

\section{Dimensions of Open Strategy}

Early notions of Open Strategy varied in their emphases. Thus Chesbrough and Appleyard (2007), in the first explicit usage of the term Open Strategy, emphasized the exchange of ideas with external actors through the combination of 'open innovation' and 'open coordination' within ecosystems. For Doz and Kosonen (2008: 75), Open Strategy is more a process requiring that ' $\ldots$ companies actively co-strategize and experiment with multiple stakeholders in line with a comprehensive architecture for staying connected with the world'. Schmitt (2010) describes 'open strategizing' as a process involving external stakeholders in issue framing, arena shaping and credibility building. Demonstrated here is a range of Open Strategy phenomena, from Chesbrough and Appleyard's (2007) focus on knowledge flows, to the more avowedly consultative approaches of Schmitt (2010) and Doz and Kosonen (2008).

These various phenomena are all captured by the two key dimensions of Whittington et al's (2011) conceptualization of Open Strategy. Thus the dimension of transparency, referring to the internal or external visibility of information about an organization's strategy, encompasses the exchange of ideas and knowledge emphasized by Chesbrough and Appleyard (2007). The dimension of inclusion, referring to internal or external consultation, embraces both the external consultation of Schmitt (2010) and the more comprehensive costrategizing of Doz and Kosonen (2008).

In the same way, the two dimensions are capable of organizing complementary themes in parallel research streams even outside the specific domain of Open Strategy. To start with transparency, researchers from the fields of reputation and impression management are exploring the role of openness towards external stakeholders: appropriately managed, greater understanding of strategy leads to more support on the part of shareholders and interest groups (Rindova and Fombrun, 1999; Benner and Zenger, 2016; Whittington, et al., 2016). From a different angle, research on new information technologies is increasingly revealing the potential of social media to enhance transparency, by increasing the visibility of internal 
conversations and creating traceable threads of exchange (Haefliger, et al., 2011; Gast and Zanini, 2012; Neeley and Leonardi, forthcoming)

Information technology also promotes inclusion. Thus strategy jamming and wiki technologies underpin recent initiatives to crowd-source strategy, involving participants both from inside (Wood and Bjelland, 2008; Stieger, et al., 2012) and from outside organizations (Newstead and Lanzerotti, 2010; Dobusch, et al., 2013; Aten and Thomas, 2016). Inclusion is, of course, a research theme that predates these new information technologies. Thus arguments from procedural justice theory have long supported the value of giving organizational members 'voice' in strategic decision-making processes (Korsgaard, et al., 1995; Kim and Mauborgne, 1998). Similarly, researchers on middle management and other employee groups have documented for some years the widespread appetite for involvement in the strategy process, and the consequent benefits in terms of better information and greater commitment (Westley, 1990; Wooldridge and Floyd, 1990; Mantere and Vaara, 2008; Laine and Vaara, 2015). At the same time, critical management theorists highlight the pressure that trends towards greater inclusion can place on employees throughout the organization (Knights and Morgan, 1990; Oakes, et al., 1998; Clegg and Kornberger, 2015).

These parallel streams of research have considerable potential to inform developing understandings of transparency and inclusion. Papers in this Special Issue already draw from earlier work on impression management (Gegenhuber and Dobusch, 2017), procedural justice (Hutter, et al., 2017) and middle management inclusion (Mack and Szulanski, 2017), as well as other traditions. Indeed, in the diversity of their approaches, these papers allow us to develop and deepen Open Strategy's two main dimensions significantly. Table 1 summarizes how each paper addresses either transparency or inclusion or, in several cases, both. These papers reveal new complexities in both these dimensions.

\section{INSERT TABLE 1 APPROXIMATELY HERE}

Transparency emerges from these papers as contingent and highly variable in form. The earlier Whittington et al (2011) paper concentrated on the broad forces tending to favour greater strategic openness in society generally. The papers of this Special Issue develop a more contingent understanding, emphasizing the particular circumstances of organizations. For example, Yakis-Douglas et al (2017) show how transparency in acquisition strategies is 
more valued by shareholders when firms are engaged in strategic initiatives that deviate from industry norms. In Appleyard and Chesbrough's (2017) analysis of Amazon and Google, the value of transparency is contingent upon organizations' evolving competences and the maturity of their markets. Similarly, Gegenhuber and Dobusch (2017) suggest that the importance of transparency ('broadcasting') changes as new ventures mature (see below).

The variability in transparency is developed in Baptista et al's (2017) examination of the roles of different kinds of information technology, such as blogs, wikis and videocasts. Such technologies yield significant gradations in transparency, particularly with regard to the extent of access, the range of topics permitted and the degree of freedom from controls and moderation. Transparency is a continuum subject to managerial choice. Also with regard also to forms of transparency, Yakis-Douglas et al (2017) usefully distinguish between 'mandatory' and 'voluntary' disclosures of strategic information. This distinction reminds us how, in many contexts, regulatory pressures have recently tended to oblige more mandatory disclosure regardless of managerial choices. Openness is not wholly discretionary. What these two papers reinforce together is a sense that transparency comes in many forms, with managers sometimes having to make careful choices about the degree to which it is allowed, but sometimes obliged to concede openness whether they like it or not.

The special issue papers deepen our understanding of inclusion as well, again revealing both contingency and variability. The papers demonstrate that inclusion is typically a precarious accomplishment, its success contingent on supportive circumstances and practices. Thus Malhotra et al (2017) and Luedicke et al (2017) both show that effectiveness in inclusion relies on various practices, such as controlled agenda-setting and issue-framing, in order to manage the risk of dysfunctional escalation of openness, for example the excessive promotion of individual interests or problems of information overload. Baptista et al (2017) encapsulate this sense of contingency by introducing the notion of 'reflexiveness': here the mechanisms of inclusion (and transparency) may be in place, but their effectiveness in day-today practice depends on organizations possessing sufficient reflexive capabilities actually to integrate open and emergent feedback into their structural arrangements.

Inclusion too comes in various forms. Important here is how Mack and Szulanski (2017) draw on Quick and Feldman's (2011) distinction between participation and inclusion in public engagement initiatives. Participation is lower-strength: it is concerned with the gathering of stakeholders' input in terms of ideas and information. Crowd-sourcing strategy (Newstead 
and Lanzerotti, 2010) is a form of participation in this sense. Inclusion is deeper, entailing the creation and sustaining of a community of interacting stakeholders. In one of their case studies, Mack and Szulanski (2017) describe inclusion as involving repeated, large-scale strategy workshops, implying a growing sense of community over time. The power of inclusion (in this definition) is demonstrated in Hutter et al's (2017) paper on Siemens' internal crowd-sourcing process: there inclusiveness in the form of active commenting and evaluation of ideas contributed to the creation of a sense of community amongst involved employees, whereas mere submission of ideas (a form of 'participation') had little or even negative effects on the sense of community. In short, inclusion in the Whittington et al (2011) sense needs to be understood as involving varying degrees of inclusiveness, with different kinds of outcomes.

What emerges from the papers in this special issue, therefore, is a strong sense of the ways in which the openness dimensions of transparency and inclusion are contingent and variable. This contingency and variability underpin many of the dilemmas and dynamics of Open Strategy to be discussed in the following sections. Before that, however, it is worth pausing to consider important boundaries to the two dimensions. In particular, Open Strategy is both more than Open Innovation and less than 'democratic' strategy.

Open Strategy draws on Open Innovation, but is not reducible to it. The focus in Open Innovation on the inflows and outflows of knowledge to support innovation (Chesbrough, 2003) involves both transparency and inclusion: information is released, debated and synthesized by many stakeholders, both internal and external. However, as Yakis-Douglas et al (2017) show, the transparency dimension of Open Strategy is relevant to strategic issues beyond just innovation, including mergers and acquisitions for example. In this sense, the socalled 'content' branch of Open Strategy is not limited to open approaches to innovation strategy, as Appleyard and Chesbrough (2017) suggest, but may extend to a range of possible strategies. Indeed, the distinction between 'content' and 'process' branches of Open Strategy is highly porous: innovation, diversification and internationalization strategies all involve processes too and are all, in principle, amenable to Open Strategy too.

On the other hand, Open Strategy is typically less than 'democratic' strategy (Hamel, 1996; Stieger, et al., 2012). Transparency and inclusion are both important ingredients for truly democratic organizations, but Open Strategy does not necessarily involve the final transfer of decision-rights (Whittington, et al., 2011). Even in the case of the 'radically open' 
Premium Cola company described by Luedicke et al (2017), where strategic information was released to both internal and external stakeholders, and both were included in the strategy conversation, ultimately the owner retained control over agendas and final decisions. As we see in Malhotra et al.'s (2017) case of strategic crowdsourcing as well, even substantial experiments in openness are liable to be carefully controlled. This tension between openness and control leads us to the discussion of Open Strategy dilemmas that follows.

\section{Dilemmas of Open Strategy}

Open Strategy has a wide range of different benefits - some of which we discussed above but it also comes with significant risks and costs, as Birkinshaw (2017) highlights. In the following, we take a closer look at these challenges by discussing five central dilemmas that are typically associated with the decision to open up strategy (see Figure 1).

\section{INSERT FIGURE 1 APPROXIMATELY HERE}

The first dilemma, which we term the dilemma of process, relates to the fact that including wider audiences in their strategy process has ambivalent effects. On the one hand, inclusiveness makes it possible to "tap into their knowledge" (Stieger et al., 2012: 46) to improve the content of strategic decisions. Several studies have documented how the involvement of wider audiences allows accessing different sources of technical expertise (Appleyard and Chesbrough, 2017), different industry-specific (Werle and Seidl, 2012; Hardy et al., 2006) or position-specific perspectives on strategic problems (Baptista et al., 2017), different ideas for potential strategic initiatives (Mack et al., 2017; Luedicke et al., 2017; Hutter et al., 2017; Malhotra et al., 2017) or different interpretations of potential solutions (Teulier and Rouleau, 2014). On the other hand, greater inclusiveness often poses significant challenges to the process of decision making. As we know from research on participation in decision making more generally (Ashmos, et al., 2002; Collier, et al., 2004), the involvement of wider audiences reduces the speed, flexibility and control over the decision making process, which in some cases might even prevent the organization from making any decision at all. In their study of Open Strategy in particular, Gegenhuber and Dobusch (2017) pointed out that greater openness often "ties up considerable organizational resources (e.g. spending time on responding to users' questions)". Stieger et al. (2012) in turn, highlight how the 
inclusion of wider audiences reduces the degree of control over the course of strategic discussions. They write: "Managers [...] must be aware that discussions can evolve in unpredictable directions and seemingly irrelevant topics can emerge that are important to employees." In particular, once a topic has been put on the agenda, it is difficult to drop it again. Similarly, Haefliger et al. (2011: 297) point out that "empowering creative, independent individuals implies indeterminate and uncertain reactions and creations in support of, or in opposition to, management's original thinking." Malhotra et al. (2017) furthermore highlight that Open Strategy processes are often particularly prone to the risk of contentious conflict manifested as "back and forth posts of negative, personal and destructive attacks" and the misuse of the strategy discourse for purposes of self-promotion with potentially paralyzing effects on the discussion. Several studies have also (implicitly or explicitly) shown how the technologies that are often required in Open Strategy processes tend to shift some of the control over the process away from the management to those who design and manipulate the social media applications (Wood and Bjelland, 2008; Dobusch and Müller-Seitz, 2012; Baptista, et al., 2017). In the literature, we can find a range of measures aimed at mitigating these negative consequences of openness by introducing different structural elements into the process, such as rules for participation (Stieger, et al., 2012; Malhotra, et al., 2017), but they typically only ameliorate rather than remove the process dilemma.

The second dilemma, which we term dilemma of commitment, concerns the fact that Open Strategy can both increase and decrease commitment to the organization's strategy. On the one hand, inviting wider audiences to participate in the development of a new strategy has been shown to have positive motivational effects and to increase commitment to the outcome of the strategy process. As Stieger et al. (2012: 46) write, "involvement with a larger number of employees in the strategy process has long been recognized as a means to create [...] stronger commitment", where sufficient "buy-in" is considered a precondition for successful implementation of strategy. On the other hand however, the practicalities of handling greater inclusiveness often also undermine the very commitment the participation is meant to create. Various studies have documented how the challenges in processing the participants' input often leads to frustrations and dissociation from the strategic discussions. Baptista et al. (2017), for example, writes about "user frustrations" when participants find that their contributions are moderated or restricted in terms of visibility. They write: "Employees were happy to engage with organizational discourse but expected in return their voice and contribution to be acknowledged and purposefully considered". Luedicke et al. (2017) in turn, 
highlight how participants lose motivation if they are eventually excluded from developments that originated from their own initiative. Such exclusion, as Dobusch and Mueller-Seitz (2014) point out, is often inevitable as decision-making processes come to a closure.

The third dilemma, which we term dilemma of disclosure, concerns the fact that greater transparency about the strategy process and its outcome has many advantages but it also carries significant risks. Being more transparent, on the one hand, increases legitimacy in face of new societal norms and regulatory requirements about transparency (Whittington, et al., 2011), serves as a means of impression management (Gegenhuber and Dobusch, 2017; Whittington et al., 2016), helps reduce problematic information asymmetries (Yakis-Douglas et al., 2016) and facilitates collaboration (Appleyard and Chesbrough, 2016; Hardy et al., 2006). On the other hand however, transparency can also undermine an organization's competitiveness (1) to the extent that competitors get hold of strategically sensitive information (Appleyard and Chesbrough, 2017), (2) to the extent that the organization gets exposed to greater regulatory influence as regulatory agencies are granted access to information about the internal workings of the organization (Meyer and Rowan, 1977; Fung, et al., 2007), and (3) to the extent that the available information, paradoxically, even reduces understanding of what is going on in the organization (Etzioni, 2010). The latter point has also been referred to as the "paradox of the information society" (Tsoukas, 1997). Tsoukas (1997) stresses that while transparency means that information is made available to wider audiences, it leaves open how this information is interpreted. The further away the respective audiences are from the context in which the information originated, the more likely that the information will be interpreted in the light of a different interpretive context resulting in conflicting interpretations. Drawing on behavioral economics, Etzioni also points out that "very often the public is unable to properly process even rather simple information because of 'wired in', congenital, systematic cognitive biases" (Etzioni, 2010: 10). Even just increasing the amount of information might reduce understanding due to information overload (Ripken, 2006: 187). In addition, Tsoukas (1997) argues that in the case of all so called "expert systems", i.e. work processes that involve specialized, codified, abstract knowledge, transparency is likely to undermine the external audiences' trust, which is necessary for these expert systems to function. He writes: "[T]he paradox is that the more information on the inner workings of an expert system observers seek to have, the less they will be inclined to trust its practitioners." (Tsoukas, 1997:835) 
The fourth dilemma, which we term the dilemma of empowerment, concerns the fact that the inclusion of wider audiences in the strategy process can be seen both as blessing and burden by the participants. On the one hand, greater inclusion offers the participants a say in matters of strategy and thereby grants them more power in the organization (Korsgaard, et al., 1995; Kim and Mauborgne, 1998; Mantere and Vaara, 2008). On the other hand however, this kind of empowerment subjects the participants to the burdens of strategy work. This includes, first of all, the expectation that the participants invest - typically in addition to their regular tasks - extra time and effort into strategy work. Luedicke et al. (2017), for example, point out that participants are often expected "to digest an excessive amount of comments".

Furthermore, being included in the strategy process also means that the participants become (formally or at least morally) accountable for the results of their work (Oakes, et al., 1998). More generally, empowering people to participate in strategy development means that they will be subjected to the "symbolic violence" of the strategy discourse resulting in changes of their identity as organizational members (Oakes, et al., 1998: 288). As Knights and Morgan (1990: 269) highlighted, people involved in strategy "are transformed into subjects who secure their sense of meaning, identity and reality [...] through participation in the discourses and practices of strategy." This means that they internalize the pressures of strategy putting them under new kinds of strain (Knights and Morgan, 1990; Oakes et al, 1998; Clegg and Kornberger, 2015).

The fifth dilemma, which we term dilemma of escalation, refers to the fact that once organizations start opening up their strategy process in selective dimensions and domains, pressures are created for other dimensions and domains to be opened up as well. In some cases such escalation might be positive to the extent that organizations might start experimenting with openness in some limited areas before engaging in, and hence benefitting from, openness on a larger scale (Haefliger, et al., 2011). However, once organizations open up in some areas they might not have the possibility anymore to restrict openness if they wanted to. Hence, organizations face the challenge that if they dilemma, on the one hand, of not opening up at all and, hence, to relinquish potential benefits of selective openness, or, on the other hand, to risk being forced to open up completely with the respective challenges or to suffer the negative consequences of disappointed expectations about openness. For example, various authors (Dobusch and Müller-Seitz, 2014; Baptista, et al., 2017) have pointed out that if people get included in the strategy process, they also expect to get access to the respective strategy information; and conversely, if people get information about the strategy process they often try to get also included in the strategy development process. Furthermore, by opening 
the strategy process to selective audiences, other audiences are likely to expect to be met with a similar degree of openness as well (Baptista, et al., 2017). Furthermore and as mentioned already above, people included in the strategy process often expect not only to contribute to the discussion of strategy but to be also involved in the actual decision making (Dobusch and Müller-Seitz, 2014; Luedicke, et al., 2017). To the extent that companies do not meet these escalating expectations of openness, they will have to deal with the disappointed expectations and potential allegations of "cheap talk" or "open washing" (Dobusch, et al., 2013).

\section{Dynamics of Open Strategy}

An organization's decision to be more open or closed on one or both dimensions is neither dichotomous nor fixed (Appleyard and Chesbrough, 2017). The dilemmas discussed in the previous section require continuous reassessment and rebalancing of the extent and mixture of the bundle of practices applied. Hence, the choice of openness is dynamic, allowing movements along and between the dimensions, towards and away from greater openness. As previously discussed, selectively increasing levels of inclusion and/ or transparency can create dilemmas such as e.g. the dilemmas of commitment or escalation. Here, new expectations of involved actors can lead to unexpected and emergent tensions which ultimately create pressures to further increase levels of openness on one or both dimensions (Baptista, et al., 2017). In addition, due to the dilemmas of process, disclosure and empowerment and dependent on internal and external contingencies, increased openness itself may become less efficient and may prompt organizations to shift back to lower levels of transparency and inclusion or even reverse to a "closed" strategizing approach. In the following, we discuss how emergent dilemmas and contingencies induce these dynamic shifts in openness based on figures $2 \mathrm{a}-2 \mathrm{~d}$ and by referring to the articles in this special issue.

\section{INSERT FIGURES 2a-2d APPROXIMATELY HERE}

The axes of figures $2 \mathrm{a}-2 \mathrm{~d}$ describe the two key dimensions of transparency and inclusion as variable in their form and extent. Traditionally, strategy making has been perceived as secretive and elitist (Whittington, et al., 2011). This closed approach, characterized by low levels of both, transparency and inclusion, is situated in the lower left area of figure $2 \mathrm{a}$. Recent cases show that more and more organizations have departed from such a closed approach. Firms take strides towards increasing inclusion and/or transparency and move along 
arrows 1, 2, or 3 as they expect beneficial outcomes of Open Strategy discussed above. Cases in the Special Issue show how firms shift along the Open-Closed continuum on one or both dimensions.

When organizations increase transparency and move along arrow 1 in figure $2 \mathrm{a}$, they choose to provide more information about their strategic decisions without giving additional actors the opportunity to participate or to be included in the decision-making process. In this special issue, Yakis-Douglas et al (2017) provide an example for such a movement along the transparency dimension. They discuss the benefits for organizations, which are voluntarily more externally transparent in post-acquisition announcements. Dobusch et al (2012) argue that such an approach, restricted to increases along the transparency dimension, is characterized by impression management intentions without the purpose of creating commitment or joint sensemaking. Organizations also take strides towards increased openness by moving along the continuum of inclusiveness (arrow 2). Siemens, for example, enabled its employees to participate in strategy formation through providing ideas and suggestions in a company-wide online initiative (Hutter, et al., 2017). Also, the public institution Land Care Research increased levels of participation in idea generation through an online-crowdsourcing initiative (Malhotra, et al., 2017).

In their review of existing studies on Open Strategy, Dobusch et al (2012) argue that most cases of increased openness combine a shift towards aspects of both dimensions, transparency and inclusion, illustrated by arrow 3 in figure $2 \mathrm{a}$. In such cases, organizations receive additional information and knowledge but also share more information. It can be argued that in the cases of Siemens and Land Care Research, the focus was on increased inclusion, but at the same time transparency was enhanced at least to some extent by providing information on the initiatives' purpose, the decision-making process and its outcomes. However, greater inclusion does not necessarily correlate with higher levels of transparency (Whittington, et al., 2011). In their study Mack and Szulanski (2017) show that in centralized organizations where the phases of idea generation and decision-making are decoupled and dominated by different groups of actors, increased participation in idea generation is still characterized by low levels of transparency.

The cases discussed above (Hutter, et al., 2017; Mack and Szulanski, 2017; Malhotra, et al., 2017; Yakis-Douglas, et al., 2017) refer to movements along one (arrows 1 and 2) or both dimensions (arrow 3) through temporary "strategic episodes" (Hendry and Seidl, 2003). 
However, some organizations are not required to shift in such a way, as they are already "born open" and constantly practice increased levels of inclusion and/or transparency over time. From its beginning, the collective "Premium Cola", for example, has enabled maximum levels of inclusion by giving every member the chance to be included in the entire strategizing process, from raising an issue to deciding on a strategic direction. At the same time radical transparency has been practiced concerning all decisions taken (Luedicke, et al., 2017). Also the online-based start-ups studied by Gegenhuber and Dobusch (2017) have chosen high levels of transparency concerning the communication of strategic information combined with practices of inclusion right from their founding.

As illustrated in figure 2a, most cases of Open Strategy refer to limited movements along the dimensions. Except for Premium Cola, which applied a bundle of practices of radical openness that could be characterized as nearly "fully open", most organizations only choose to increase inclusion and/or transparency to limited degrees. As highlighted in the previous section, allowing only limited movements on the two dimensions can result in several dilemmas - e.g. the dilemma of escalation and the dilemma of commitment - by raising expectations of involved individuals (Baptista, et al., 2017). If unmet, these expectations can create dissatisfaction, frustration and pressures that provoke strides towards even higher levels of transparency and inclusion. If an organization practices moderate levels of transparency by only selectively sharing previously exclusive information, this can trigger additional questions, and requirements of even more information and ultimately pressures additional movements on arrow 1. Similarly, shifts on arrow 2 towards moderate degrees of participation - e.g. through submissions of ideas, suggestions, and participation in discussions - might raise actors' expectations to be also included in further decision-making. This dilemma of escalation might force organizations to move further along arrow 2 as shown in figure $2 \mathrm{a}$ (Baptista, et al., 2017). The same dynamics might also be driven by the dilemma of commitment. Allowing only limited levels of transparency or inclusion may noticeably reduce newly gained commitment and motivation when participants are eventually excluded from developments that originated from their own contributions or find them restricted in visibility (Dobusch and Müller-Seitz, 2014; Baptista, et al., 2017). Again, needs for even more transparency or inclusion arise, pressuring firms to further move along arrows 1 and 2.

It is not only limited movement along the transparency or inclusion dimension that can pose dilemmas of escalation and commitment and trigger dynamic shifts. Also restrictively increasing openness on only one of the two dimensions can create pressures to open up the 
other dimension as well (see figure 2b). Multiple studies show that sharing more information with a larger audience not only leads to requests of even greater transparency but can simultaneously raise demands of increased participation, driving organizations to move along arrow 4 (Dobusch and Müller-Seitz, 2014; Baptista, et al., 2017; Luedicke, et al., 2017). The same is true for organizations, which increase inclusiveness but do not provide sufficient information to allow meaningful participation. Luedicke et al (2017) show that the opportunities and commitment of individuals to participate, to raise relevant strategic issues and to direct the debate are dependent on access to relevant information about strategic issues. Hence, increased inclusion raises needs and expectations of increased levels of transparency, which have to be met by subsequent shifts along arrow 5 .

The dilemmas of Open Strategy might not only drive movements towards higher levels of openness. Under some conditions, increased openness may become less efficient or even dysfunctional (Appleyard and Chesbrough, 2017). The dilemmas of disclosure, empowerment and process posed by internal and external contingencies may hinder organizations in capturing value from increased openness (Birkinshaw, 2017) and induce movements back to lower levels of transparency and inclusion or even completely reverse to a "closed" approach (see figures $2 \mathrm{c}$ and $2 \mathrm{~d}$ ).

Figure 2c shows reversals from increased transparency. As discussed in the previous section, if organizations are practicing higher levels of transparency, the dilemmas of disclosure and empowerment can counteract positive effects due to deliberations of competitiveness (Appleyard and Chesbrough, 2017), information overload and the inability of individuals to appropriately process and interpret the additional information (Tsoukas, 1997; Etzioni, 2010; Luedicke, et al., 2017). In such cases, increasingly sharing information with wider audiences becomes inefficient and organizations are pressured to reverse and reduce transparency along arrows 6,7 or 8 .

In addition, reversals to lower levels of inclusiveness (figure $2 \mathrm{~d}$ ) can be prompted by the dilemmas of empowerment and process, which make outcomes of inclusion less beneficial or relevant. Empowering people to participate can also require digesting an excessive amount of information, investing free time or being accountable for the results of suggestions. These additional burdens might reduce individuals' motivation and beneficial consequences of being included in the strategy process (Stieger, et al., 2012; Luedicke, et al., 2017). As also suggested by insights from related research on participatory organizations (Rothschild and 
Whitt, 1986; O'Mahony and Ferraro, 2007; Chen, 2016), Luedicke et al (2017) show that explicit attempts towards openness may revert to less inclusive practices, such as e.g. authoritarian agenda setting and decision-making. These dynamics are reflected in movements along arrows 8, 9 and 10 in figure $2 \mathrm{~d}$. Also the dilemma of process may induce such reversals. In their study Gegenhuber and Dobusch (2017) show that over time, start ups shifted from a more inclusive, dialoguing-led approach back to a broadcasting-led approach focused on communicating strategic information. Over time the establishment and growth of the organizations required additional resources tied up in inclusive practices, which made a reversal back to the focus on transparency (arrow 9) more efficient.

Summarizing and reflecting the various dynamics discussed above illustrates the complexity and contingencies inherent in the concept of Open Strategy. Firms might increasingly become amalgamations of more or less closed and more or less open approaches to strategizing over time. Introducing the appropriate level of openness requires strategic agility in the sense that organizations are required to stay flexible, ready to assess past choices and change their approach in the light of new developments and circumstances (Doz and Kosonen, 2008). The decisions whether an organization introduces openness as well as the chosen level of openness on one or both dimensions are driven by the dilemmas highlighted and dependent on internal and external contingencies such as e.g. the competitive and regulatory environment (Appleyard and Chesbrough, 2017), the phase in the organizational life-cycle (Appleyard and Chesbrough, 2017; Gegenhuber and Dobusch, 2017), organizational structures (Mack and Szulanski, 2017), and organizational and individual capabilities (Baptista, et al., 2017; Luedicke, et al., 2017). Baptista et al (2017) argue that in order to avoid tensions from restrictive openness, organizations need to develop the capability to adjust structurally. By focusing on the use of social media they show that over time the development of reflexiveness is a necessary capability for organizations to manage and integrate emergent feedback in their internal structures (Baptista, et al., 2017). In addition organizational access to communication channels for information and knowledge sharing (Felin and Zenger, 2014), or decentralized organizational structures (Mack and Szulanski, 2017) support successful shifts to increased transparency and inclusion. Finally, the choice of openness on both dimensions depends on the capabilities of individuals involved. As Luedicke et al (2017) show, the ability and willingness of individuals to process the provided amount of information and to actively participate along the entire strategy process are important factors which should not be taken for granted. 


\section{Research Agenda}

As described in the preceding sections, recent research has shown Open Strategy to be a multifaceted and highly dynamic phenomenon. Compared to the initial contributions on the topic (Chesbrough and Appleyard, 2007; Doz and Kosonen, 2008; Whittington, et al., 2011), we now have a much more sophisticated and nuanced understanding of the different dimensions, dilemmas and dynamics of Open Strategy. However, we are still only at the beginning of the exploration. Not only are there many aspects of Open Strategy that have not been systematically examined yet but the very field of Open Strategy itself is still in the process of development. Organizations are only just starting to use open practices and new open practices are continuously emerging. Hence, more so than in other fields of study, research on Open Strategy is dealing with a phenomenon in motion. This makes this type of research both particularly exciting but also particularly challenging. Against this background we will sketch out an agenda for future research on Open Strategy and highlight the theoretical and methodological resources available for its exploration.

At present we can identify six promising areas of research that we will briefly characterize together with some exemplary research questions for each. The first area of research concerns the different practices of Open Strategy. While existing research has already started to take stock of the diversity of open practices such as jamming (Wood and Bjelland, 2008), blogging (Gegenhuber and Dobusch, 2017), online forums (Stieger, et al., 2012), contests and community platforms (Hutter, et al., 2017; Malhotra, et al., 2017), strategy announcements (Yakis-Douglas, et al., 2017), or inter-organizational workshops (Werle and Seidl, 2012; Werle and Seidl, 2015), new open practices are continuously emerging - particularly as new information technologies are becoming available (Haefliger, et al., 2011). Hence, researchers interested in Open Strategy might want to capture the range of open practices available to organizations and examine trends in the use of these practices. Birkinshaw (2017) for example suggests it might be worth investigating if distinctive open practices need to be applied when addressing either internal or external audiences and if the employed practices vary in their effectiveness when firm boundaries are crossed. Acknowledging the important role of information technology in Open Strategy, researchers might also examine in more detail how open practices are affected by the emergence of new technologies and how different technologies are involved in the enactment of these practices (Whittington, 2014). In addition, we need to learn more about the various effects of different open practices on the organization, groups and individuals involved. As practices are typically not employed in 
isolation (Seidl and Whittington, 2014; Jarzabkowski, et al., 2016), we also need to explore how particular open practices relate to other open practices or other organizational practices such as accounting practices or public relations practices. Related to all of these questions, we also need to understand the different contingencies that affect the emergence, use, bundling and effects of open practices. Existing research has already provided first indications for contingencies that might be relevant in that respect, such as the organization's degree of centralization (Mack and Szulanski, 2017), the organization's stage in its life cycle (Gegenhuber and Dobusch, 2017) or the type of organization (Dobusch and Müller-Seitz, 2014).

The second area of research concerns the different dilemmas of Open Strategy. While we have already acknowledged the need to consider the risks and costs of openness (Birkinshaw, 2017) and identified central dilemmas of Open Strategy, we still know very little about how these dilemmas are managed both on the organizational and on the individual level. Previous studies have already provided some first insights in this respect, e.g. the use of mitigation practices (Malhotra, et al., 2017), counterbalancing practices (Luedicke, et al., 2017), the shift between openness and closure (Dobusch and Müller-Seitz, 2014) or the development of new forms of reflexivity (Baptista, et al., 2017). We also need to learn more about the effects of these dilemmas and their handling on the level of the individual, group and organization. As these dilemmas typically do not operate independently from each other, future research might also explore how the different dilemmas relate to each other. For example, the handling of the dilemma of escalation is likely to affect how the other dilemmas play out. Related to all of these questions, future research also needs to explore the different contingencies affecting the extent to which particular openness dilemmas are experienced and managed.

The third area of research concerns the different dynamics of Open Strategy. While we have identified already basic dynamics along the two dimensions of Open Strategy, future research could explore how these dynamics play out over longer periods of time. We might find that organizations exhibit different patterns of moving between openness and closure in the different dimensions over time. We are also just at the beginning of understanding the underlying mechanisms of the dynamics of Open Strategy, such as the inherent dilemmas of Open Strategy or the societal drivers (Whittington, et al., 2016). Furthermore, future research might look into the effects of these dynamics on the individual, group or organization. We also need to learn more about the different means of handling the dynamics of openness. For example, shifting from greater to less openness is likely to be met with resistance from the 
affected parties (Baptista, et al., 2017). Beyond that we also need to explore the different contingencies that affect the type, direction and speed of the dynamics of Open Strategy.

The fourth area of research concerns the relation between Open Strategy and strategy content. Most research on Open Strategy has concentrated on the particularities of the strategy process but little attention has been paid so far on the way in which Open Strategy affects the content of strategy. For example, one might speculate that greater inclusiveness might lead to better strategies as more perspectives are being taken into account and a greater pool of knowledge is being drawn upon (Stieger, et al., 2012:46). At the same time, the processual challenges in handling great numbers of participants could also undermine the quality of strategic decision making (Huber, 1990). Future research might also explore the reverse relationship, i.e. how the strategy content might affect Open Strategy practices. Depending on the particular strategic issues concerned, organizations might choose different open practices (e.g. Yakis-Douglas, et al., 2017). Related to the preceding two research areas, we might also explore how the dynamics and dilemmas of Open Strategy affect the content of strategy and how the content of strategy affects the dynamics and dilemmas in turn.

The fifth area of research concerns the implications of Open Strategy for strategy practitioners. As we have seen in the preceding sections, Open Strategy poses new kinds of challenges. In particular, there are the challenges associated with the different dilemmas and dynamics of openness. Against this background, future research should investigate what implications this has for the kind of competences that strategists - whether in-house functional specialists, strategy consultants or managers in general - are required to have. We might speculate that greater inclusiveness is associated with an increasing need for competences in process management, communication and motivation (Whittington, et al., 2011). In addition to that, we would speculate that strategists often will need particular technological competences in order to be able to make effective use of the new kinds of technologies that are typically used in Open Strategy processes (Whittington, 2014). Apart from those with formal strategic responsibilities, greater inclusion also has consequences for the competences required for the newly-included lower level employees. Besides technological skills required to be able to participate in technologically moderated processes (Hutter, et al., 2017), participants might also need to be trained in the use of different strategy tools and in the interpretation of strategy information, if they are to contribute effectively. Future research could also investigate what implication greater openness in strategy has for the status of the strategy profession. For example, greater transparency about the strategy 
process might remove some of the mysticism about strategy work and thereby undermine the particular status of the strategist. Similarly, greater inclusiveness might remove status difference between the formal strategists and the ordinary participants to the strategy process. Related to that, future research could also examine the implications of greater openness on the distribution of power between different organizational members. For example, we might find that power in the strategy process shifts from the formal strategists to those people that control the technological infrastructure, e.g. the IT officers (Whittington, 2014).

The sixth area of research, which is linked to all the other areas of research, concerns comparative studies on Open Strategy. Given that we are only just at the beginning of capturing the new phenomenon of Open Strategy, most research so far has contented itself with focusing on a single contexts - even where it examined several cases (e.g. Gegenhuber and Dobusch, 2017). Future research might be more ambitious in terms of exploring differences in how Open Strategy plays out in different contexts. While we have already mentioned above the need to explore different contingencies of Open Strategy, there is a particular opportunity for conducting comparative studies of Open Strategy in different contexts. Most importantly, we should examine differences in the use and effect of particular open practices in different cultural contexts, different industries or different organizational contexts. We could also examine differences in the use of open practices by different types of practitioners (Jarzabkowski, et al., 2007). More generally, we could also compare how open practices are used in Open Strategy to how they are used in other domains such as Open Innovation (Dahlander and Gann, 2010), Open Government (Janssen et al., 2012) or Open Science (David, 1998). As open practices are often transferred from one domain to another it is important to understand to what extent the same practices might have different effects in different domains. An example of such a comparative study is Dobusch et al. (2015), who compared Open Strategy to Open Innovation.

Together, this agenda of central areas of research offers a great range of avenues for further investigations into this exciting new phenomenon of Open Strategy. Given the diversity of foci, analytical levels and temporal dimensions of the respective research questions, putting this research agenda into action requires a variety of different theoretical and methodological approaches. Existing research has already provided us with indications of some particularly fruitful approaches. In terms of theories, researchers have drawn on practice theory (Luedicke, et al., 2017; Mack and Szulanski, 2017), community of practice literature (Malhotra, et al., 2017), sensemaking perspectives (Werle and Seidl, 2012; Teulier and Rouleau, 2013), 
communication theory (Werle and Seidl, 2012; Malhotra, et al., 2017), social exchange theory (Hutter, et al., 2017), impression management theory (Gegenhuber and Dobusch, 2017), information economics (Yakis-Douglas, et al., 2017) and industrial economics (Appleyard and Chesbrough, 2017). This demonstrates the plurality of theoretical perspectives that might be applied in research on Open Strategy. In addition to that, there is a host of additional theoretical perspectives that could be mobilized. For example, institutional theory (Suddaby, et al., 2013; Smets, et al., 2015) might be helpful in examining more macro aspects of Open Strategy such as trends in the use of open practices or general shifts in the delineation of the strategy profession. On the other end of the spectrum, we might think of more micro perspectives such as conversation analysis or ethnomethodology (Samra-Fredericks, 2015), which would allow theorizing the influence of open practices and technologies on the microlevel interactions of the involved participants.

This diversity in theoretical perspectives is paralleled by a diversity of methodological resources available to researchers of Open Strategy. Existing studies have drawn on a wide range of different methodologies and methods ranging from traditional ethnographies (Werle and Seidl, 2012), to netnographies (Gegenhuber and Dobusch, 2017; Luedicke, et al., 2017), to action research (Malhotra, et al., 2017) and to various quantitative methods (Hutter, et al., 2017; Yakis-Douglas, et al., 2017). In addition to that, there is a host of other methods that, depending on the particular research question, could be fruitfully employed, such as network analysis (Hautz, 2015) to capture how the use of open practices might affect organizational and personal social networks, historical methods (Ericson, et al., 2015) to trace shifts in open practices over time or narrative analysis (Rouleau, 2015) to examine how Open Strategy affects the identities of the different participants.

\section{Conclusion}

The increasing adoption of more open approaches to strategy demands a response from the research community. The promise of Open Strategy is attractive and its potential is widespread. The organizational importance of Open Strategy is utterly consistent with the contemporary Strategy-as-Practice ambition to connect macro-level trends with micro-level activity, and the issues it raises are amenable to theoretical approaches ranging from industrial economics to institutional theory. The combination of macro and micro lends itself to a wide range of methodologies, from ethnography to quantification. In short, Open Strategy offers a rich and impactful research agenda. 
However, we argue here for critical inquiry founded on a definition of Open Strategy that appreciates its dilemmas and dynamics. Open Strategy is not unequivocally a good thing. Greater transparency and inclusion come with characteristic problems; organizational moves are not just one way. There are sharp dilemmas of process, commitment, empowerment, disclosure and escalation. Organizations may switch between the dimensions of transparency and inclusion, and even retreat from openness altogether.

This combination of macro-level reach with complexity and ambivalence should be a powerful motivation for research. The work we have reviewed in this article, appearing both in this Special Issue and elsewhere, offers a valuable platform for further inquiry. We hope that, as knowledge accumulates, the phenomenon of Open Strategy itself will be rendered more transparent.

\section{Acknowledgements}

The guest editors would like to thank Leonhard Dobusch for his helpful feedback on earlier drafts of this paper. They are also grateful to the editor-in-chief Tomi Laamanen and former editor James Robins for their continued support of this special issue. We would also like to thank all and the following reviewers without whose work this issue would not have been possible:

[list here]. 


\section{Tables}

Table 1: Special Issue Papers by Dimensions of Transparency and Inclusion

\begin{tabular}{|c|c|c|c|}
\hline $\begin{array}{l}\text { Special Issue } \\
\text { Paper }\end{array}$ & Focus & Transparency & Inclusion \\
\hline $\begin{array}{l}\text { Appleyard and } \\
\text { Chesbrough (2017) }\end{array}$ & $\begin{array}{l}\text { Reversion from } \\
\text { Open Innovation } \\
\text { Strategy }\end{array}$ & $\begin{array}{l}\text { the (free) access to } \\
\text { project results by } \\
\text { outsiders (transparency) }\end{array}$ & $\begin{array}{l}\text { the reliance on assets outside } \\
\text { of the firm's boundaries }\end{array}$ \\
\hline $\begin{array}{l}\text { Baptista, Wilson, } \\
\text { Galliers and } \\
\text { Bynghall (2017) }\end{array}$ & $\begin{array}{l}\text { Social media and } \\
\text { reflexiveness in } \\
\text { Open Strategy }\end{array}$ & $\begin{array}{l}\text { transparency (wider } \\
\text { access to content and } \\
\text { information) }\end{array}$ & $\begin{array}{l}\text { inclusiveness (broader } \\
\text { involvement of stakeholders) }\end{array}$ \\
\hline $\begin{array}{l}\text { Gegenhuber and } \\
\text { Dobusch (2017) }\end{array}$ & $\begin{array}{l}\text { Impression } \\
\text { management modes } \\
\text { in Open Strategy } \\
\text { over time }\end{array}$ & $\begin{array}{l}\text { Broadcasting } \\
\text { (transparently } \\
\text { communicating relevant } \\
\text { information) }\end{array}$ & $\begin{array}{l}\text { dialoguing (asking users for } \\
\text { opinions and engaging in } \\
\text { conversation), and including } \\
\text { (involving external audiences } \\
\text { in decision-making). }\end{array}$ \\
\hline $\begin{array}{l}\text { Hutter, Nketia and } \\
\text { Fueller (2017) }\end{array}$ & $\begin{array}{l}\text { how virtual } \\
\text { participation } \\
\text { affects } \\
\text { organizational } \\
\text { belongingness }\end{array}$ & & $\begin{array}{l}\text { Virtual participation takes } \\
\text { two types: active e.g. posting } \\
\text { messages and passive e.g. } \\
\text { only the reading of } \\
\text { information. }\end{array}$ \\
\hline $\begin{array}{l}\text { Luedicke, } \\
\text { Husemann, Furnari, } \\
\text { Ladstaetter (2017) }\end{array}$ & $\begin{array}{l}\text { Radically open } \\
\text { strategizing } \\
\text { practices }\end{array}$ & & $\begin{array}{l}\text { Radically open practices, } \\
\text { with no barriers to } \\
\text { participation: i.e. distributed } \\
\text { agenda setting, substantial } \\
\text { participation, and consensual } \\
\text { decision-making. }\end{array}$ \\
\hline $\begin{array}{l}\text { Mack and Szulanski } \\
\text { (2017) }\end{array}$ & $\begin{array}{l}\text { Participation and } \\
\text { inclusion in } \\
\text { centralized and } \\
\text { decentralized } \\
\text { organizations }\end{array}$ & $\begin{array}{l}\text { the visibility of } \\
\text { information about an } \\
\text { organization's strategy, } \\
\text { during the formulation } \\
\text { process and with regard } \\
\text { to the strategy finally } \\
\text { produced }\end{array}$ & $\begin{array}{l}\text { participation is about } \\
\text { increasing stakeholders' } \\
\text { input for decisions; inclusion } \\
\text { is about creating and } \\
\text { sustaining a community of } \\
\text { interacting stakeholders }\end{array}$ \\
\hline $\begin{array}{l}\text { Malhotra, } \\
\text { Majchrzak and } \\
\text { Niemiec } \\
(2017)\end{array}$ & $\begin{array}{l}\text { Managing } \\
\text { contention and self- } \\
\text { promotion risks in } \\
\text { Open Strategy } \\
\text { processes }\end{array}$ & & $\begin{array}{l}\text { online collaborative } \\
\text { crowdsourcing process to } \\
\text { allow integration of varied } \\
\text { external stakeholders }\end{array}$ \\
\hline $\begin{array}{l}\text { Yakis-Douglas, } \\
\text { Angwin, Ahn and } \\
\text { Meadows (2017) }\end{array}$ & $\begin{array}{l}\text { Transparency during } \\
\text { merger and } \\
\text { acquisition } \\
\text { processes }\end{array}$ & $\begin{array}{l}\text { Public announcements } \\
\text { during M\&A deals, both } \\
\text { 'mandatory' and } \\
\text { 'voluntary. }\end{array}$ & \\
\hline
\end{tabular}




\section{Figures}

\section{Figure 1: Central Dilemmas of Open Strategy}

\begin{tabular}{|c|c|c|c|}
\hline $\begin{array}{l}\text { Granting access to wider } \\
\text { sources of knowledge }\end{array}$ & $\longleftarrow$ & Dilemma of process & $\begin{array}{c}\text { Compromising speed, flexibility } \\
\text { and control over the strategy } \\
\text { development process }\end{array}$ \\
\hline $\begin{array}{l}\text { Creating commitment by } \\
\text { inviting contributions }\end{array}$ & $\longleftarrow$ & Dilemma of commitment & $\longrightarrow \begin{array}{c}\text { Undermining commitment due } \\
\text { to unmet expectations about } \\
\text { impact of contributions }\end{array}$ \\
\hline $\begin{array}{l}\text { Responding to expectations } \\
\text { about disclosure of strategy } \\
\text { information }\end{array}$ & $\longleftarrow$ & Dilemma of disclosure & $\begin{array}{c}\text { Undermining } \\
\text { competitiveness, trust and } \\
\text { understanding }\end{array}$ \\
\hline $\begin{array}{c}\text { Granting wider audiences } \\
\text { a say in strategy } \\
\text { development }\end{array}$ & $\longleftarrow$ & Dilemma of empowerment & $\rightarrow \begin{array}{c}\text { Burdening wider audiences } \\
\text { with the pressures of strategy }\end{array}$ \\
\hline $\begin{array}{l}\text { Realizing benefits of } \\
\text { openness in selected } \\
\text { areas of strategy }\end{array}$ & $\longleftarrow$ & Dilemma of escalation & $\begin{array}{l}\text { Creating escalating } \\
\text { expectations about } \\
\text { increasing openness }\end{array}$ \\
\hline
\end{tabular}


Figure 2: Dynamics of Open Strategy: Movements Along and Between the Dimensions

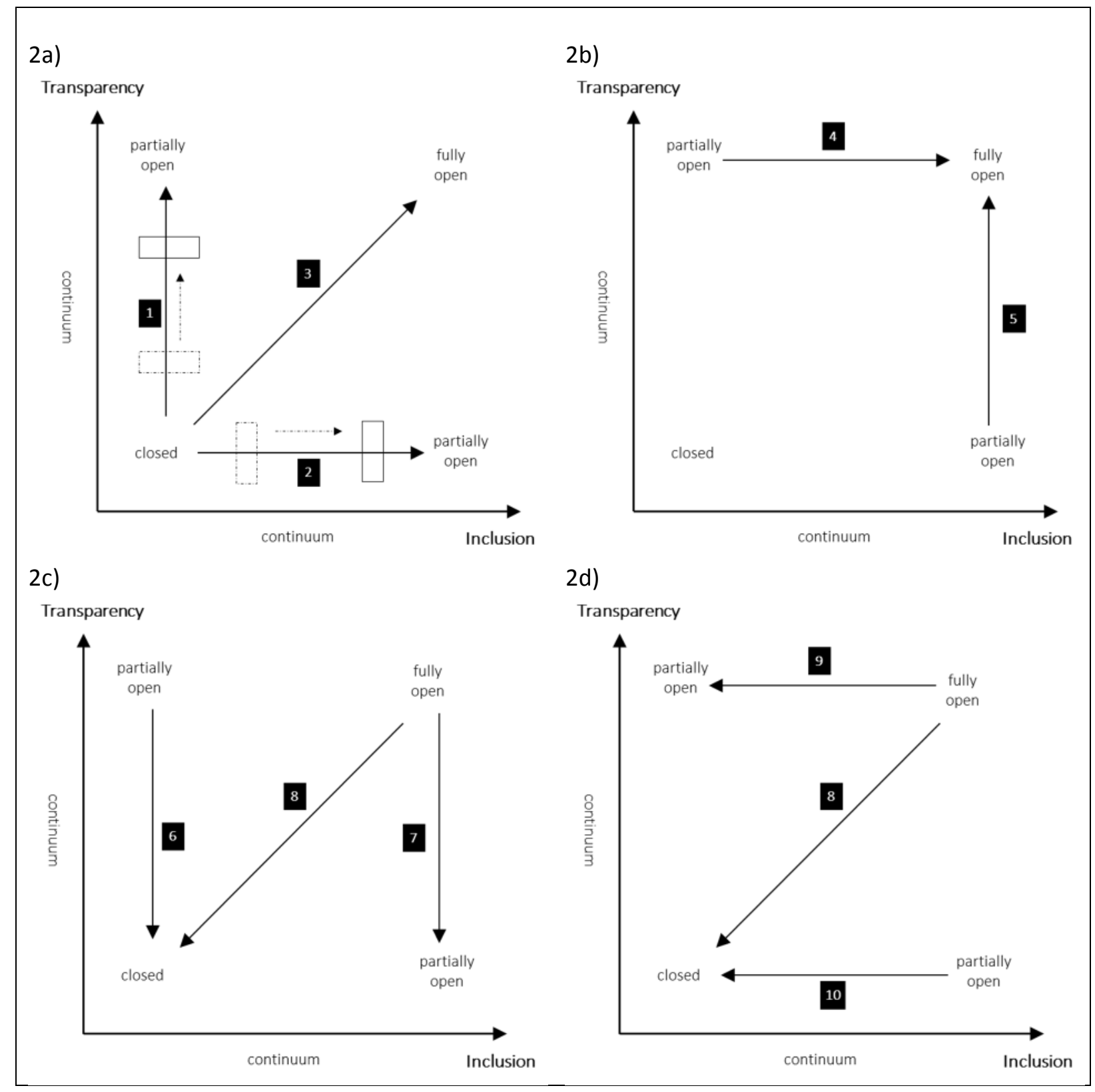




\section{References}

Appleyard, M.M. and Chesbrough, H.W., 2017. The Dynamics of Open Strategy: From Adoption to Reversion. Long Range Planning http://dx.doi.org/10.1016/j.lrp.2016.07.004.

Ashmos, D.P., Duchon, D., Mcdaniel Jr, R.R. and Huonker, J.W., 2002. What a Mess! Participation as a Simple Managerial Rule to 'Complexify' Organizations. Journal of Management Studies 39 (2), 189206.

Aten, K. and Thomas, G.F., 2016. Crowdsourcing Strategizing: Communication Technology Affordances and the Communicative Constitution of Organizational Strategy. International Journal of Business Communication 10.1177/2329488415627269.

Baptista, J., Wilson, A.D., Galliers, R.D. and Bynghall, S., 2017. Social Media and the Emergence of Reflexiveness as a New Capability for Open Strategy. Long Range Planning http://dx.doi.org/10.1016/j.lrp.2016.07.005.

Benner, M.J. and Zenger, T., 2016. The Lemons Problem in Markets for Strategy. Strategy Science 1 (2), 71-89.

Birkinshaw, J., 2017. Reflections on Open Strategy. Long Range Planning.

Chen, K.K., 2016. "Plan Your Burn, Burn Your Plan": How Decentralization, Storytelling, and Communification Can Support Participatory Practices. The Sociological Quarterly 57 (1), 71-97.

Chesbrough, H., 2003.Open Innovation: The New Imperative for Creating and Profiting from Technology. 1st ed. edn. Boston: Harvard Business School Press.

Chesbrough, H.W. and Appleyard, M.M., 2007. Open Innovation and Strategy. . California Management Review 50 (1), 57-76.

Clegg, S. and Kornberger, M., 2015. Analytical Frames for Studying Power in Strategy as Practice and Beyond in Handbook of Strategy as Practice, D. Golsorkhi, L. Rouleau, Seidl D. and E. Vaara (eds), 389-404. Cambridge: Cambridge University Press.

Collier, N., Fishwick, F. and Floyd, S.W., 2004. Managerial Involvement and Perceptions of Strategy Process. Long Range Planning 37 (1), 67-83.

Dobusch, L., Gegenhuber, T. and Bauer, R., 2013. Between Crowd and Community: Organizing Online Collaboration in Open Innovation and Beyond. Academy of Management Proceedings.

Dobusch, L. and Müller-Seitz, G., 2012. Strategy as a Practice of Thousands? The Case of Wikimedia. Academy of Management Best Paper Proceedings.

2014. Closing Open Strategy. Strategy as a Practice of Thousands in the Case of Wikimedia. Working Paper.

Doz, Y. and Kosonen, M., 2008. The Dynamics of Strategic Agility: Nokia's Rollercoaster Experience. California Management Review 50 (3), 95-118.

Ericson, M., Melin, L. and Popp, A., 2015. Studying Strategy as Practice through Historical Methods in Cambridge Handbook of Strategy as Practice, D. Golsorkhi, L. Rouleau, David Seidl and E. Vaara (eds), 506-519. Cambridge, UK: Cambridge University Press.

Etzioni, A., 2010. Is Transparency the Best Disinfectant? Journal of Political Philosophy 18 (4), 389404.

Felin, T. and Zenger, T.R., 2014. Closed or Open Innovation? Problem Solving and the Governance Choice. Research Policy 43 (5), 914-925.

Fung, A., Graham, M. and Weil, D., 2007.Full Disclosure: The Perils and Promise of Transparency. Cambridge: Cambridge University Press.

Gast, A. and Zanini, M., 2012. The Social Side of Strategy. McKinsey Quarterly May1-15.

Gegenhuber, T. and Dobusch, L., 2017. Making an Impression through Openness: How Open StrategyMaking Practices Change in the Evolution of New Ventures. Long Range Planning http://dx.doi.org/10.1016/j.lrp.2016.09.001. 
Haefliger, S., Monteiro, E., Foray, D. and Von Krogh, G., 2011. Social Software and Strategy. Long Range Planning 44 (5/6), 297-316.

Hamel, G., 1996. Strategy as Revolution. Harvard Business Review (July-August), 69-82.

Hautz, J., 2015. Opening up the Strategy Process - a Network Perspective. Academy of Management Proceedings 2015 (1).

Hendry, J. and Seidl, D., 2003. The Structure and Significance of Strategic Episodes: Social Systems Theory and the Routine Practices of Strategic Change. Journal of Management Studies 40 (1), 175196.

Huber, G.P., 1990. A Theory of the Effects of Advanced Information Technologies on Organizational Design, Intelligence, and Decision Making. The Academy of Management Review 15 (1), 47-71.

Hutter, K., Nketia, B.A. and Füller, J., 2017. Falling Short with Participation - Different Effects of Ideation, Commenting, and Evaluating Behavior on Open Strategizing. Long Range Planning http://dx.doi.org/10.1016/j.lrp.2016.08.005.

Jarzabkowski, P., Balogun, J. and Seidl, D., 2007. Strategizing: The Challenges of a Practice Perspective. Human Relations 60 (1), 5-27.

Jarzabkowski, P., Kaplan, S., Seidl, D. and Whittington, R., 2016. On the Risk of Studying Practices in Isolation: Linking What, Who, and How in Strategy Research. Strategic Organization 14 (3), 248259.

Ketokivi, M. and Castaner, X., 2004. Strategic Planning as an Integrative Device. Administrative Science Quarterly 49 (3), 337-365.

Kim, C.W. and Mauborgne, R., 1998. Procedural Justice, Strategic Decision Making, and the Knowledge Economy. Strategic Management Journal 19 (4), 323-338.

Knights, D. and Morgan, G., 1990. The Concept of Strategy in Sociology: A Note of Dissent. Sociology 24 (3), 475-483.

Korsgaard, M.A., Schweiger, D.M. and Sapienza, H.J., 1995. Building Commitment, Attachment, and Trust in Strategic Decision-Making Teams: The Role of Procedural Justice. Academy of Management Journal 38 (1), 60-84.

Laine, P.-M. and Vaara, E., 2015. Participation in Strategy Work in Handbook of Strategy as Practice, D. Golsorkhi, L. Rouleau, Seidl D. and E. Vaara (eds). Cambridge: Cambridge University Press.

Luedicke, M.K., Husemann, K.C., Furnari, S. and Ladstaetter, F., 2017. Radically Open Strategizing: How the Premium Cola Collective Takes Open Strategy to the Extreme. Long Range Planning http://dx.doi.org/10.1016/j.lrp.2016.07.001.

Mack, D.Z. and Szulanski, G., 2017. Opening Up: How Centralization Affects Participation and Inclusion in Strategy Making. Long Range Planning.

Malhotra, A., Majchrzak, A. and Niemiec, R.M., 2017. Using Public Crowds for Open Strategy Formulation: Mitigating the Risks of Knowledge Gaps. Long Range Planning http://dx.doi.org/10.1016/j.lrp.2016.06.004.

Mantere, S. and Vaara, E., 2008. On the Problem of Participation in Strategy: A Critical Discursive Perspective. Organization Science 19 (2), 341-358.

Meyer, J.W. and Rowan, B., 1977. Institutionalized Organizations: Formal Structure as Myth and Ceremony American Journal of Sociology 83 (2), 340-363.

Neeley, T. and Leonardi, P., forthcoming. Enacting Knowledge Strategy through Social Media Use: The Paradox of Non-Work Interactions. Strategic Management Journal.

Newstead, B. and Lanzerotti, L., 2010. Can You Open-Source Your Strategy? Harvard Business Review (October), 32.

O'mahony, S. and Ferraro, F., 2007. The Emergence of Governance in an Open Source Community. Academy of Management Journal 50 (5), 1079-1106.

Oakes, L.S., Townley, B. and Cooper, D.J., 1998. Business Planning as Pedagogy: Language and Control in a Changing Institutional Field. Administrative Science Quarterly 257-292. 